\title{
Prognostic Factors and Treatment Results of High-Grade Osteosarcoma in Norway: A Scope Beyond the "Classical" Patient
}

\author{
Kjetil Berner, ${ }^{1,2}$ Kirsten Sundby Hall, ${ }^{1}$ Odd R. Monge, ${ }^{3}$ Harald Weedon-Fekjær, ${ }^{4}$ \\ Olga Zaikova, ${ }^{5}$ and Øyvind S. Bruland ${ }^{1,6}$ \\ ${ }^{1}$ Department of Oncology, Oslo University Hospital, Norwegian Radium Hospital, 0424 Oslo, Norway \\ ${ }^{2}$ The Norwegian Cancer Registry, 0304 Oslo, Norway \\ ${ }^{3}$ Department of Oncology, Haukeland University Hospital, 5020 Bergen, Norway \\ ${ }^{4}$ Oslo Center for Biostatistics and Epidemiology, Research Support Services, Oslo University Hospital, 0424 Oslo, Norway \\ ${ }^{5}$ Department of Orthopedics, Oslo University Hospital, Norwegian Radium Hospital, 0424 Oslo, Norway \\ ${ }^{6}$ Institute of Clinical Medicine, University of Oslo, 0318 Oslo, Norway \\ Correspondence should be addressed to Øyvind S. Bruland; oyvind.bruland@medisin.uio.no
}

Received 26 September 2014; Accepted 12 January 2015

Academic Editor: Eugenie S. Kleinerman

Copyright ( 2015 Kjetil Berner et al. This is an open access article distributed under the Creative Commons Attribution License, which permits unrestricted use, distribution, and reproduction in any medium, provided the original work is properly cited.

Purpose. A retrospective study of prognostic factors and treatment outcome of osteosarcoma (OS) during modern chemotherapy era with focus on patients with primary metastatic disease, nonextremity localisation, or age $>40$ years (nonclassical OS). Methods. A nationwide cohort, comprising 424 high-grade Norwegian bone OS patients, was based on registry sources supplemented with clinical records from hospitals involved in sarcoma management between 1975 and 2009. Results. Only 48\% were younger patients with tumour in the extremities and without metastasis at diagnosis (classical OS). A considerable discrepancy in survival between classical and nonclassical OS was observed: $61 \%$ versus $26 \% 10$-year sarcoma specific survival. Twice as many of the former received both adequate surgery and chemotherapy compared to the latter. This could only partly explain the differences in survival due to inherent chemoresistance in primary metastatic disease and a higher rate of local relapse among patients with axial tumours. Metastasis at diagnosis, increased lactate dehydrogenase, age $>40$ years, and tumour size above median value were all adverse prognostic factors for overall survival. Conclusion. We confirm a dramatic difference in outcome between classical and nonclassical high-grade OS patients, but treatment variables could only partly explain the dismal outcome of the latter.

\section{Introduction}

Multimodal treatment including multiagent chemotherapy has been essential to improve the survival of high-grade osteosarcoma (OS) patients [1-7]. The literature has predominantly focused on "classical OS" (COS); that is, extremity localized primary tumour, high-grade histology, age below 40 years, and no detectable metastasis at primary diagnosis. The prognoses are dismal for other subgroups of OS, that is, the "nonclassical OS" (NCOS) [5, 8-10]. Patients with axial OS may die due to lack of local control, even without detectable metastases. The chemoresistant disease in patients presenting with overt metastases is also an unsolved clinical challenge. The poor tolerance to adequate chemotherapy in the elderly represents another hurdle.

In this paper we report outcome of patients with NCOS during the modern chemotherapy era. Our cohort represents an unselected Norwegian OS population [10]. The purpose of this study was to compare patients with COS and NCOS with respect to patient characteristics and prognostic factors related to treatment outcome. To our knowledge only a few nationwide studies have previously been published [10-17]. None of these have specifically addressed a scope beyond the classical patient. 


\section{Material and Methods}

2.1. Patient Cohort. We have analysed 424 histologically verified high-grade bone OS patients diagnosed in Norway between 1975 and 2009 embracing all subgroups of NCOS (Figure 1), including secondary OS [10]. Variables relevant to this study were retrospectively validated based on multiple and partly overlapping data and registry sources supplemented with clinical records from all Norwegian hospitals involved in sarcoma management. Most patients were treated at the Norwegian Radium Hospital [10]. As expected, we have not reached full completeness regarding clinical information for all patients in the study (see Table 1), especially among patients diagnosed with OS during the 1970s. The database is located at the Norwegian Cancer Registry (NCR).

2.2. Demographic and Tumour Related Variable. All demographic and tumour related variables are presented in Tables $1-2$.

Tumour size was measured from surgical specimens and/or radiographic images at diagnosis and defined as the maximum length of tumour in $\mathrm{cm}$. Duration of symptoms was the interval in months between first symptom and time of biopsy. Unfortunately we could not dichotomise this interval into "patients delay" and "doctor's delay" [18] due to lack of accurate information in too many of the clinical case records. Median tumour size above $10 \mathrm{~cm}$ and median duration of symptoms longer than 3 months were defined as elevated values in the analyses.

Serum Alkaline Phosphatase (ALP) and Serum Lactate Dehydrogenase $(L D H)$. Normal range, measured in international units at time of diagnosis, for ALP and LDH, was considered in line with the common Nordic Reference interval from May 2003 [19], that is, ALP: 0-17 years, $<400 \mathrm{U} / \mathrm{L}$; $>17$ years, $<105$ U/L; LDH: 0-10 years, <400 U/L; 11-70 years, <205 U/L; $>70$ years, <255 U/L. Analyses before May 2003 needed a 60 and $50 \%$ reduction in values, respectively, to be compatible with the above mentioned thresholds.

2.3. Treatment Variables. Before the introductions of the prospective clinical trials of the Scandinavian Sarcoma Group (SSG) in 1980 [5], several patients were treated according to the "CAMOS" regime [12]. During the study period, seven consecutive chemotherapy protocols were running: SSG II [20], SSG VIII [21], ISG/SSG I [22], ISG/SSG II [23], SSG XIV [24], Euroboss 1 [25], and the EURAMOS-1 [25-27], respectively. Patients not eligible for inclusion in the protocols were considered for individualized chemotherapy adjusted for age and toxicity.

The Euroboss 1 protocol still remains active in many European countries, and for the EURAMOS-1 only the results from the good responder arm have been reported [27, 28]. However, recent data show that adding ifosfamide and etoposide to high-dose methotrexate, cisplatin, and doxorubicin is associated with additional morbidity with no impact on survival outcome for the poor responders [29].

Adequate primary treatment was defined as having received both adequate chemotherapy and adequate surgery.

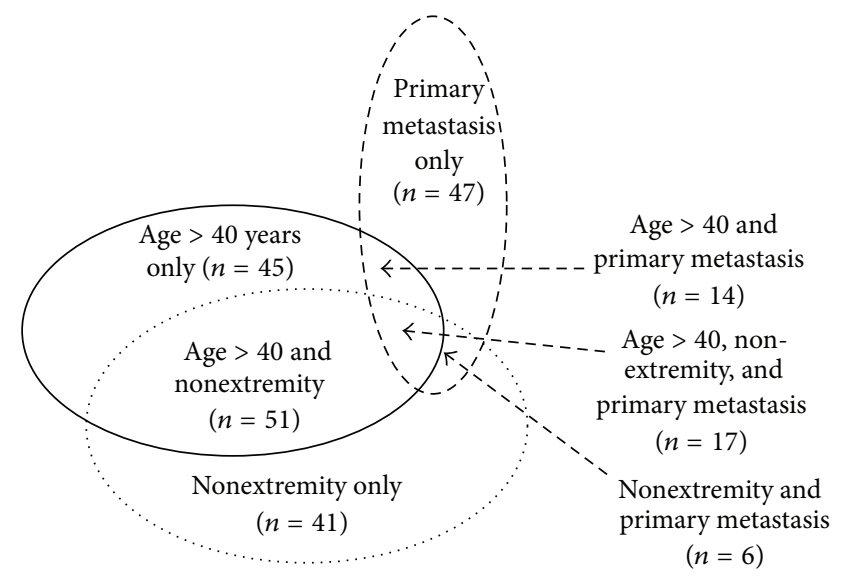

FIGURE 1: Nonclassical high-grade osteosarcoma (221 patients) with illustration of the overlaps between subgroups.

All treatment had to be given before metastatic disease or local relapse was verified among patients without primary metastatic disease. The below mentioned treatment variables were assessed both in relation to all patients that actually received chemotherapy (pre- and/or postoperative) and/or surgery and for all patients in the cohort regardless of given treatment or not (Tables 3-5 and Figures 2-4). We have not chosen to include radiotherapy in our definition of adequate primary treatment, since OS is known to be relatively resistant to such therapy [30]. However, there still may be a place for radiotherapy as local treatment of unresectable OS, following marginal or intralesional surgery, or as palliation of metastases [30-32].

Adequate chemotherapy was defined as receiving at least six courses of chemotherapy containing a minimum of two of the following drugs: high-dose methotrexate (at least $8 \mathrm{~g} / \mathrm{m}^{2}$ ), doxorubicin, cisplatin, or ifosfamide in line with a previous definition by Sæter and Bruland [33]. These four drugs are most commonly used worldwide, even though there is still no international consensus on their optimal combination $[9,34]$. We did not consider the CAMOS regimen [12] as adequate chemotherapy in this study, as compared to the current standard for active chemotherapy. We have not included histological response analysis in this study (see Section 4).

Adequate surgery implied surgical removal of primary tumour with wide or marginal margins [35], as defined by the surgeon and pathologist, and was always attempted. In this analysis we dichotomised between amputation (last surgery performed) and limb-sparing surgery, including 13 cases of rotationplasty. Patients with metastatic disease at time of diagnosis were in need for a complete surgical remission for both primary tumour and metastases, mostly to the lungs, in order to be classified as having received adequate surgery. However, in three cases we accepted just adequate surgery towards primary tumour when preoperative chemotherapy had "melted away" visible lung metastases present at time of diagnosis and with no thoracotomy performed.

2.4. Statistical Analyses. All prognostic variables were initially investigated by descriptive statistics. Relative risk (RR) 
TABLE 1: Characteristics of nonclassical and classical osteosarcoma (OS) patients, 1975-2009.

\begin{tabular}{|c|c|c|c|}
\hline & Nonclassical OS patients (\%) & Classical OS patients (\%) & All patients ${ }^{\mathrm{a}}(\%)$ \\
\hline All patients & $221(52)$ & $203(48)$ & $424(100)$ \\
\hline \multicolumn{4}{|l|}{ Gender } \\
\hline Female & $108(49)$ & $70(34)$ & $178(42)$ \\
\hline Male & $113(51)$ & $133(66)$ & $246(58)$ \\
\hline \multicolumn{4}{|c|}{ Axial versus extremity } \\
\hline Extremity & $106(48)$ & $203(100)$ & $309(73)$ \\
\hline Axial & $115(52)$ & 0 & $115(27)$ \\
\hline \multicolumn{4}{|c|}{ Primary metastatic disease } \\
\hline No & $134(61)$ & $203(100)$ & $337(80)$ \\
\hline Yes & $84(39)$ & 0 & $84(20)$ \\
\hline \multicolumn{4}{|l|}{ Age } \\
\hline$\leq 40$ years & $94(43)$ & $203(100)$ & $297(70)$ \\
\hline$>40$ years & $127(57)$ & 0 & $127(30)$ \\
\hline \multicolumn{4}{|l|}{ Tumour size } \\
\hline$\leq 10 \mathrm{~cm}$ & $84(52)$ & $102(56)$ & $186(54)$ \\
\hline$>10 \mathrm{~cm}$ & $78(48)$ & $80(44)$ & $158(46)$ \\
\hline \multicolumn{4}{|c|}{ Duration of symptoms } \\
\hline$\leq 3$ months & $86(45)$ & $120(62)$ & $206(53)$ \\
\hline$>3$ months & $107(55)$ & $73(38)$ & $180(47)$ \\
\hline \multicolumn{4}{|l|}{ Pathologic fracture } \\
\hline No & $187(85)$ & $178(88)$ & $365(86)$ \\
\hline Yes & $34(15)$ & $25(12)$ & $59(14)$ \\
\hline \multicolumn{4}{|l|}{ ALP } \\
\hline Normal & $62(42)$ & $104(68)$ & $166(55)$ \\
\hline Elevated & $87(58)$ & $48(32)$ & $135(45)$ \\
\hline \multicolumn{4}{|l|}{$\mathrm{LDH}$} \\
\hline Normal & $73(51)$ & $87(61)$ & $160(56)$ \\
\hline Elevated & $70(49)$ & $56(39)$ & $126(44)$ \\
\hline \multicolumn{4}{|l|}{ Histology } \\
\hline Osteoblastic & $97(44)$ & $94(47)$ & $191(46)$ \\
\hline Chondroblastic & $30(14)$ & $25(13)$ & $55(13)$ \\
\hline Fibroblastic & $20(9)$ & $21(11)$ & $41(10)$ \\
\hline Other & $73(33)$ & $59(30)$ & $132(32)$ \\
\hline
\end{tabular}

${ }^{a}$ Missing values equal the difference between the summarized number from each subgroup in the fourth column and the total patients in the study.

and chi square analyses were applied. Survival analyses using Kaplan-Meier estimates [36], log rank tests [37], and Cox regression [38] were used to analyse overall survival, sarcoma specific survival (SSS), and event free survival (EFS). To identify the interactions between different prognostic factors, both univariate and multivariate Cox regression were applied. Overall survival was calculated from date of diagnosis [10] until death from any cause, while sarcoma specific death or treatment-related death was the endpoint of SSS. Patients with synchronous or metachronous skeletal osteosarcomas [39] were not censored in these analyses. EFS was calculated from date of diagnosis until the date of first metastasis, local recurrence, sarcoma specific death, or treatment-related death whichever occurred first. Patients with primary metastatic OS were not included in the analyses regarding EFS.

The endpoint for all survivors in this study was set to July 2013 using updated registries [10], to prevent bias due to nonidentical followup of patients with few or frequent appointments. The mean and median followup time for survivors were 18 and 17 years, respectively.

Statistically significant prognostic variables in univariate analysis were included into multivariate backward Coxregression analyses. However, the three main subgroups of NCOS (Figure 1) were also included in the last step of the latter Cox model, independent of $P$ values, to show their main estimated values and related confidence intervals. The Cox proportion hazard assumption was evaluated using KaplanMeier plots. The potential effect of missing values was evaluated using multiple MCMC imputation [40]. The statistical analyses were conducted using SPSS version 22 (SPSS Inc., Chicago, IL) and Stata version 13.1 (Stata corporation, College Station, TX).

2.5. Ethical Approval. The Regional Ethical Committee was informed, although the study did not require a formal ethical approval since the data registration was in line with the legitimate mandate of the NCR [10]. 
TABLE 2: Relative risk analysis among nonclassical osteosarcoma (OS) patients; primary metastatic disease, nonextremity localisation, and age $>40$ years.

\begin{tabular}{|c|c|c|c|c|c|c|c|c|c|c|c|}
\hline \multirow{4}{*}{$\begin{array}{l}\text { Axial versus extremit } \\
\text { Extremity }\end{array}$} & \multicolumn{2}{|c|}{ Nonclassical OS } & \multicolumn{3}{|c|}{ Primary metastatic disease } & \multicolumn{3}{|c|}{ Nonextremity localisation } & \multicolumn{3}{|c|}{ Age $>40$ years } \\
\hline & $\mathrm{RR}^{\mathrm{a}}\left(95 \% \mathrm{CI}^{\mathrm{b}}\right)$ & $P^{\mathrm{c}}$ & $N^{\mathrm{d}}$ & $\mathrm{RR}^{\mathrm{a}}\left(95 \% \mathrm{CI}^{\mathrm{b}}\right)$ & $P^{\mathrm{c}}$ & $N^{\mathrm{d}}$ & $\mathrm{RR}^{\mathrm{a}}\left(95 \% \mathrm{CI}^{\mathrm{b}}\right)$ & $P^{\mathrm{c}}$ & $N^{\mathrm{d}}$ & $\mathrm{RR}^{\mathrm{a}}\left(95 \% \mathrm{CI}^{\mathrm{b}}\right)$ & $P^{\mathrm{c}}$ \\
\hline & & & & & & & & & & & \\
\hline & & & 61 & 1 & & 0 & & & 59 & 1 & \\
\hline Axial & & & 23 & $1.0(0.7-1.5)$ & 0.953 & 115 & & & 68 & $3.4(2.5-4.6)$ & $<0.001$ \\
\hline \multicolumn{12}{|c|}{ Primary metastatic disease } \\
\hline No & & & 0 & & & 89 & 1 & & 94 & 1 & \\
\hline Yes & & & 84 & & & 23 & $1.0(0.7-1.5)$ & 0.857 & 31 & $1.4(0.9-2.1)$ & 0.102 \\
\hline \multicolumn{12}{|l|}{ Age } \\
\hline$\leq 40$ years & & & 53 & 1 & & 47 & 1 & & 0 & & \\
\hline$>40$ years & & & 31 & $1.3(0.9-1.8)$ & 0.109 & 68 & $3.1(2.4-4.1)$ & $<0.001$ & 127 & & \\
\hline \multicolumn{12}{|l|}{ Tumour size } \\
\hline$\leq 10 \mathrm{~cm}$ & 1 & & 18 & 1 & & 51 & 1 & & 48 & 1 & \\
\hline$>10 \mathrm{~cm}$ & $1.1(0.9-1.4)$ & 0.436 & 38 & $1.6(1.3-2.0)$ & $<0.001$ & 26 & $0.7(0.5-1.0)$ & 0.026 & 42 & $1.0(0.8-1.3)$ & 0.870 \\
\hline \multicolumn{12}{|c|}{ Duration of symptoms } \\
\hline$\leq 3$ months & 1 & & 43 & 1 & & 35 & 1 & & 41 & 1 & \\
\hline$>3$ months & $1.5(1.2-1.8)$ & $<0.001$ & 34 & $0.9(0.7-1.2)$ & 0.632 & 61 & $1.6(1.3-1.9)$ & $<0.001$ & 65 & $1.5(1.2-1.8)$ & $<0.001$ \\
\hline \multicolumn{12}{|l|}{ Pathologic fracture } \\
\hline No & 1 & & 68 & 1 & & 111 & 1 & & 102 & 1 & \\
\hline Yes & $1.3(0.8-2.0)$ & 0.364 & 16 & $1.5(0.9-2.4)$ & 0.124 & 4 & $0.2(0.1-0.5)$ & 0.001 & 25 & $1.7(1.1-2.8)$ & 0.025 \\
\hline \multicolumn{12}{|l|}{ ALP } \\
\hline Normal & 1 & & 18 & 1 & & 34 & 1 & & 34 & 1 & \\
\hline Elevated & $1.9(1.4-2.4)$ & $<0.001$ & 46 & $1.9(1.5-2.4)$ & $<0.001$ & 43 & $1.4(1.1-1.8)$ & 0.017 & 47 & $1.5(1.1-1.9)$ & 0.003 \\
\hline \multicolumn{12}{|l|}{$\mathrm{LDH}$} \\
\hline Normal & 1 & & 21 & 1 & & 43 & 1 & & 41 & 1 & \\
\hline Elevated & $1.3(1.0-1.6)$ & 0.098 & 41 & $1.7(1.4-2.2)$ & $<0.001$ & 31 & $0.9(0.7-1.3)$ & 0.667 & 37 & $1.1(0.8-1.5)$ & 0.473 \\
\hline \multicolumn{12}{|l|}{ Histology } \\
\hline Osteoblastic & 1 & & 44 & 1 & & 48 & 1 & & 51 & 1 & \\
\hline Chondroblastic & $1.0(0.9-1.1)$ & 0.622 & 8 & $1.1(1.0-1.3)$ & 0.124 & 20 & $0.9(0.7-1.0)$ & 0.135 & 18 & $0.9(0.8-1.1)$ & 0.404 \\
\hline Fibroblastic & $1.0(0.9-1.1)$ & 0.816 & 8 & $1.0(0.9-1.2)$ & 0.610 & 9 & $1.0(0.9-1.2)$ & 0.656 & 13 & $1.0(0.8-1.1)$ & 0.530 \\
\hline Other & $0.9(0.8-1.1)$ & 0.423 & 23 & $1.1(0.9-1.4)$ & 0.270 & 38 & $0.9(0.8-1.2)$ & 0.476 & 44 & $0.9(0.7-1.1)$ & 0.220 \\
\hline
\end{tabular}

${ }^{\mathrm{a}}$ Relative risk, ${ }^{\mathrm{b}}$ confidence interval, ${ }^{\mathrm{c}} \mathrm{P}$ value, and ${ }^{\mathrm{d}}$ number of patients.

TABLE 3: Patients who received inadequate treatment dependent of subgroup of high-grade osteosarcoma (OS).

\begin{tabular}{|c|c|c|c|c|c|}
\hline & \multirow{2}{*}{ Patients $^{\mathrm{a}}$} & \multirow{2}{*}{ Not adequate treatment $\left(\%^{\mathrm{b}}\right)$} & \multicolumn{3}{|c|}{ Reason for inadequacy } \\
\hline & & & Surgery $\left(\%^{c}\right)$ & Chemotherapy $\left(\%^{\mathrm{c}}\right)$ & Both $\left(\%^{\mathrm{c}}\right)$ \\
\hline Classical OS & 200 & $56(28)$ & $0(0)$ & $52(93)$ & $4(7)$ \\
\hline Nonclassical OS & 218 & $146(67)$ & $32(22)$ & $45(31)$ & $69(47)$ \\
\hline Nonextremity only & 39 & $20(51)$ & $9(45)$ & $6(30)$ & $5(25)$ \\
\hline Primary metastasis only & 46 & $23(50)$ & $15(65)$ & $2(9)$ & $6(26)$ \\
\hline Age $>40$ only & 45 & $32(71)$ & $0(0)$ & $24(75)$ & $8(25)$ \\
\hline Several factors combined & 88 & $71(81)$ & $8(11)$ & $13(18)$ & $50(71)$ \\
\hline
\end{tabular}

${ }^{a}$ Six uncertain cases were not included. ${ }^{b}$ In $\%$ of cases from second column. ${ }^{c}$ In $\%$ of all cases of inadequate treatment for each subgroup.

\section{Results}

3.1. Patient Characteristics. As shown in Table 1, 221 patients were NCOS (52\%) and 203 were COS (48\%). The main characteristics of these patients are also reported in Table 1, with a further description of the NCOS in Figure 1 and Table 2. The three overlapping ellipses in Figure 1 comprise age above
40 years at time of diagnosis, primary metastatic disease, or nonextremity localized primary tumour, each divided into four parts, with their associated numbers of patients. This is in order to illustrate the overlapping parts between the three subgroups of NCOS, for example, 127 patients above 40 years of age at time of diagnosis $(45+14+17+51)$. However, only 45 of these patients had extremity localized primary tumour 
TABle 4: Univariate Kaplan-Meier and Cox-regression analysis of ten-year overall survival and event-free survival according to different characteristics of all high-grade osteosarcoma.

\begin{tabular}{|c|c|c|c|c|c|c|c|c|}
\hline & \multicolumn{4}{|c|}{ Overall survival } & \multicolumn{4}{|c|}{ Event-free survival } \\
\hline & $\begin{array}{c}\text { Patients } \\
(\%)\end{array}$ & $\begin{array}{c}10 \text { years in } \% \\
\left(95 \% \mathrm{CI}^{\mathrm{a}} \text { in } \%\right)\end{array}$ & $\begin{array}{c}\mathrm{RR}^{\mathrm{b}} \\
\left(95 \% \mathrm{CI}^{\mathrm{a}}\right)\end{array}$ & $P^{\mathrm{c}}$ & $\begin{array}{c}\text { Patients } \\
\text { (\%) }\end{array}$ & $\begin{array}{c}10 \text { years in \% } \\
\left(95 \% \mathrm{CI}^{\mathrm{a}} \text { in \%) }\right.\end{array}$ & $\begin{array}{c}\mathrm{RR}^{\mathrm{b}} \\
\left(95 \% \mathrm{CI}^{\mathrm{a}}\right)\end{array}$ & $P^{\mathrm{c}}$ \\
\hline Year of diagnosis & & & & 0.010 & & & & 0.003 \\
\hline 1975-1979 & $64(15)$ & $27(17-38)$ & $1.7(1.2-2.4)$ & & $59(17)$ & $27(16-39)$ & $2.0(1.3-3.0)$ & \\
\hline 1980-1989 & $121(29)$ & $36(27-44)$ & $1.6(1.1-2.1)$ & & $91(27)$ & $33(24-43)$ & $1.7(1.2-2.4)$ & \\
\hline 1990-1999 & $103(24)$ & $46(36-55)$ & $1.2(0.8-1.6)$ & & $81(24)$ & $43(32-54)$ & $1.4(0.9-2.0)$ & \\
\hline 2000-2009 & $136(32)$ & $47(37-56)$ & 1 & & $109(32)$ & $49(39-59)$ & 1 & \\
\hline Gender & & & & 0.605 & & & & 0.433 \\
\hline Female & $178(42)$ & $43(36-51)$ & 1 & & $134(39)$ & $45(37-53)$ & 1 & \\
\hline Male & $246(58)$ & $39(32-45)$ & $1.1(0.8-1.4)$ & & $206(61)$ & $36(30-43)$ & $1.1(0.8-1.5)$ & \\
\hline Axial versus extremity & & & & $<0.001$ & & & & $<0.001$ \\
\hline Extremity & $309(73)$ & $47(41-53)$ & 1 & & $248(73)$ & $46(39-52)$ & 1 & \\
\hline Axial & $115(27)$ & $23(16-32)$ & $2.1(1.6-2.7)$ & & $92(27)$ & $25(16-34)$ & $2.1(1.6-2.8)$ & \\
\hline Primary metastasis & & & & $<0.001$ & & & & \\
\hline No & $337(80)$ & $48(43-54)$ & 1 & & & & & \\
\hline Yes & $84(20)$ & $11(6-19)$ & $3.1(2.4-4.1)$ & & & & & \\
\hline Age & & & & $<0.001$ & & & & $<0.001$ \\
\hline$\leq 40$ years & $297(70)$ & $50(44-56)$ & 1 & & $244(72)$ & $47(41-53)$ & 1 & \\
\hline$>40$ years & $127(30)$ & $18(12-26)$ & $2.7(2.1-3.5)$ & & $96(28)$ & $21(13-30)$ & $2.5(1.8-3.3)$ & \\
\hline Tumour size & & & & 0.005 & & & & 0.035 \\
\hline$\leq 10 \mathrm{~cm}$ & $186(54)$ & $50(43-57)$ & 1 & & $168(58)$ & $47(39-54)$ & 1 & \\
\hline$>10 \mathrm{~cm}$ & $158(46)$ & $38(30-45)$ & $1.5(1.1-2.0)$ & & $120(42)$ & $35(26-45)$ & $1.4(1.0-1.9)$ & \\
\hline Duration of symptoms & & & & 0.542 & & & & 0.444 \\
\hline$\leq 3$ months & $206(53)$ & $45(38-52)$ & 1 & & $163(53)$ & $42(34-49)$ & 1 & \\
\hline$>3$ months & $180(47)$ & $38(31-45)$ & $1.1(0.8-1.4)$ & & $146(47)$ & $38(30-46)$ & $1.1(0.8-1.5)$ & \\
\hline Pathologic fracture & & & & 0.119 & & & & 0.492 \\
\hline No & $365(86)$ & $42(37-47)$ & 1 & & $297(87)$ & $40(35-46)$ & 1 & \\
\hline Yes & $59(14)$ & $34(22-46)$ & $1.3(0.9-1.8)$ & & $43(13)$ & $36(22-51)$ & $1.2(0.8-1.7)$ & \\
\hline ALP & & & & $<0.001$ & & & & 0.001 \\
\hline Normal & $166(55)$ & $51(43-58)$ & 1 & & $148(62)$ & $49(40-57)$ & 1 & \\
\hline Elevated & $135(45)$ & $26(18-33)$ & $2.0(1.5-2.7)$ & & $89(38)$ & $29(20-39)$ & $1.8(1.3-2.4)$ & \\
\hline $\mathrm{LDH}$ & & & & $<0.001$ & & & & 0.020 \\
\hline Normal & $160(56)$ & $48(40-56)$ & 1 & & $85(38)$ & $47(39-55)$ & 1 & \\
\hline Elevated & $126(44)$ & $28(20-36)$ & $1.7(1.3-2.3)$ & & $139(62)$ & $30(20-40)$ & $1.5(1.1-2.1)$ & \\
\hline Adequate chemotherapy & & & & $<0.001$ & & & & $<0.001$ \\
\hline Yes & $249(59)$ & $57(50-63)$ & 1 & & $198(58)$ & $56(48-62)$ & 1 & \\
\hline No & $170(40)$ & $17(12-23)$ & $3.4(2.7-4.4)$ & & $137(40)$ & $17(11-24)$ & $3.9(3.0-5.2)$ & \\
\hline Uncertain & $5(1)$ & $40(5-75)$ & $1.2(0.4-3.9)$ & & $5(1)$ & $40(5-75)$ & $2.1(0.8-5.7)$ & \\
\hline Adequate surgery & & & & $<0.001$ & & & & $<0.001$ \\
\hline Yes & $305(72)$ & $55(49-60)$ & 1 & & $277(81)$ & $48(41-53)$ & 1 & \\
\hline No & $108(25)$ & $4(2-10)$ & $7.0(5.4-9.2)$ & & $53(16)$ & $6(2-14)$ & $4.9(3.5-6.8)$ & \\
\hline Uncertain & $11(3)$ & $9(1-33)$ & $2.9(1.5-5.6)$ & & $10(3)$ & 0 & $3.4(1.8-6.6)$ & \\
\hline Adequate primary treatment & & & & $<0.001$ & & & & $<0.001$ \\
\hline Yes & $216(51)$ & $65(58-71)$ & 1 & & $188(55)$ & $58(50-65)$ & 1 & \\
\hline No & $202(47)$ & $15(10-21)$ & $4.8(3.7-6.2)$ & & $147(43)$ & $18(12-24)$ & $4.3(3.2-5.7)$ & \\
\hline Uncertain & $6(2)$ & $29(4-61)$ & $2.0(0.7-5.5)$ & & $5(2)$ & $17(1-52)$ & $2.8(1.1-6.9)$ & \\
\hline Formal inclusion in trial & & & & $<0.001$ & & & & $<0.001$ \\
\hline Yes & $170(40)$ & $59(51-66)$ & 1 & & $144(42)$ & $55(47-63)$ & 1 & \\
\hline No & $254(60)$ & $28(23-34)$ & $2.4(1.9-3.2)$ & & $196(58)$ & $29(22-35)$ & $2.5(1.8-3.3)$ & \\
\hline
\end{tabular}

${ }^{\mathrm{a}}$ Confidence interval, ${ }^{\mathrm{b}}$ relative risk, and ${ }^{\mathrm{c}} \log$ rank test. 
TABLE 5: Multivariate Cox-regression analysis of prognostic factors and treatment-related variables for overall survival and event-free survival. All high-grade osteosarcomas.

\begin{tabular}{|c|c|c|c|c|}
\hline \multirow[b]{2}{*}{ Variables $^{\mathrm{a}}$} & \multicolumn{2}{|c|}{ Overall survival } & \multicolumn{2}{|c|}{ Event-free survival } \\
\hline & $\begin{array}{c}\mathrm{RR}^{\mathrm{b}} \\
\left(95 \% \mathrm{CI}^{\mathrm{c}}\right)\end{array}$ & $P^{\mathrm{d}}$ & $\begin{array}{c}\mathrm{RR}^{\mathrm{b}} \\
\left(95 \% \mathrm{CI}^{\mathrm{c}}\right)\end{array}$ & $P^{\mathrm{d}}$ \\
\hline \multicolumn{5}{|l|}{ Adequate primary treatment } \\
\hline Yes & 1 & & 1 & \\
\hline No & $3.6(2.3-5.4)$ & $<0.001$ & $6.6(3.9-11.1)$ & $<0.001$ \\
\hline Uncertain & $5.0(1.2-21.8)$ & 0.031 & $5.5(1.3-23.5)$ & 0.022 \\
\hline Elevated LDH & $1.5(1.1-2.1)$ & 0.015 & $1.7(1.2-2.4)$ & 0.002 \\
\hline Primary metastatic disease & $2.3(1.5-3.4)$ & $<0.001$ & & \\
\hline \multicolumn{5}{|l|}{ Year of diagnosis } \\
\hline 1975-1979 & $1.5(0.8-2.8)$ & 0.195 & $0.7(0.4-1.4)$ & 0.315 \\
\hline 1980-1989 & $2.1(1.3-3.2)$ & 0.002 & $2.0(1.2-3.2)$ & 0.005 \\
\hline 1990-1999 & $1.7(1.1-2.7)$ & 0.023 & $1.7(1.0-2.8)$ & 0.048 \\
\hline 2000-2009 & 1 & & 1 & \\
\hline Age $>40$ years & $1.5(1.0-2.2)$ & 0.041 & $1.0(0.6-1.5)$ & 0.930 \\
\hline Tumour size $>10 \mathrm{~cm}$ & $1.4(1.0-2.0)$ & 0.046 & & \\
\hline Axial primary tumour & $1.4(0.9-2.2)$ & 0.124 & $1.1(0.7-1.8)$ & 0.587 \\
\hline
\end{tabular}

${ }^{\mathrm{a}}$ Reference values in line with Table $4 .{ }^{\mathrm{b}}$ Relative risk, ${ }^{\mathrm{c}}$ confidence interval, and ${ }^{\mathrm{d}} P$ value.

with no detectable metastasis at primary diagnoses. Similarly, 17 patients presented with all three elements of NCOS.

The male to female ratio in the classical group was 1.9 compared to 1.0 among the NCOS. The latter had about the same gender balance in its three groups. We observed a significantly higher rate of axial OS among patients above 40 years (Table 2 ), as previously reported $[9,10,17]$. As presented in Table 2, we neither identified any significant differences in the percentage of patients with primary metastatic disease dependent on OS in axial versus appendicular skeleton $(\mathrm{RR}=$ $1.0)$ nor due to age $(R R=1.3)$. Primary metastatic disease was most commonly in the lungs only (approximately $80 \%$ ), otherwise developed in bone and lungs (six cases), bone only (ten cases), and one case with a soft tissue metastasis.

As demonstrated in Table 2, there were no significant differences in tumour size between COS and the total cohort of NCOS patients $(\mathrm{RR}=1.1)$ in contrast to time to diagnosis $(R R=1.5)$. Patients with OS in the weight-bearing extremity skeleton had five times increased risk of a pathologic fracture compared to patients with an axial tumour $(\mathrm{RR}=0.2)$. Also elderly patients had increased risk for a pathologic fracture $(R R=1.7)$. Patients with pathological fractures had slightly larger tumours (median $11 \mathrm{~cm}$, range $21 \mathrm{~cm}$ ) compared to all patients (median $10 \mathrm{~cm}$, range $32 \mathrm{~cm}$ ). The four cases of pathological fractures in the axial skeleton (Table 2) were all due to radiation-induced OS.

NCOS patients (all subgroups) had increased ALP levels compared to COS, while no corresponding significant differences were found regarding $\mathrm{LDH}$, except for patients with primary metastatic disease $(\mathrm{RR}=1.7)$.

3.2. Treatment-Overall Results. Table 3 outlines the extent of treatment administered to patients in the different groups of OS. 216 patients received adequate primary treatment from
TABLE 6: Univariate Cox-regression analysis of overall survival among all adequate treated high-grade osteosarcoma patients.

\begin{tabular}{lccc}
\hline & Patients (\%) & $\mathrm{RR}^{\mathrm{a}}\left(95 \% \mathrm{CI}^{\mathrm{b}}\right)$ & $P^{\mathrm{c}}$ \\
\hline Gender & & & \\
$\quad$ Female & $84(39)$ & 1 & \\
$\quad$ Male & $132(61)$ & $1.9(1.1-3.0)$ & 0.012 \\
$\begin{array}{l}\text { Axial versus extremity } \\
\quad \text { Extremity }\end{array}$ & $183(85)$ & 1 & \\
$\quad$ Axial & $33(15)$ & $1.3(0.7-2.2)$ & 0.455 \\
$\begin{array}{l}\text { Primary metastatic disease } \\
\quad\end{array}$ & $188(87)$ & 1 & \\
$\quad$ No & $28(13)$ & $2.9(1.7-4.8)$ & $<0.001$ \\
$\quad$ Yes & $187(87)$ & & \\
Age & & 1 & \\
$\quad \leq 40$ years & $29(13)$ & $1.3(0.7-2.3)$ & 0.402 \\
$\quad>40$ years & & \\
\hline${ }^{\mathrm{a}}$ Relative risk, ${ }^{\mathrm{b}}$ confidence interval, and ${ }^{\mathrm{c}} P$ value. &
\end{tabular}

1975 to 2009, and twice as many COS received adequate treatment compared to NCOS (Figure 4(d)), fully displayed in Table 6.

COS. Adequate surgery was performed in all except four cases (Table 3). Two patients had intralesional margin after surgery of humerus OS: one amputation and one limb sparing surgery, respectively. The latter patient received postoperative radiotherapy, $50 \mathrm{~Gy}$. A third patient was wrongly classified as low grade OS, received no chemotherapy, and operated with a Kotz-prosthesis of femur, but with intralesional margin. The primary histology was later revised to high-grade OS when she was diagnosed with a local relapse and subsequently lung metastases. The fourth patient died of toxicity due to neoadjuvant chemotherapy before surgery was performed. Among 


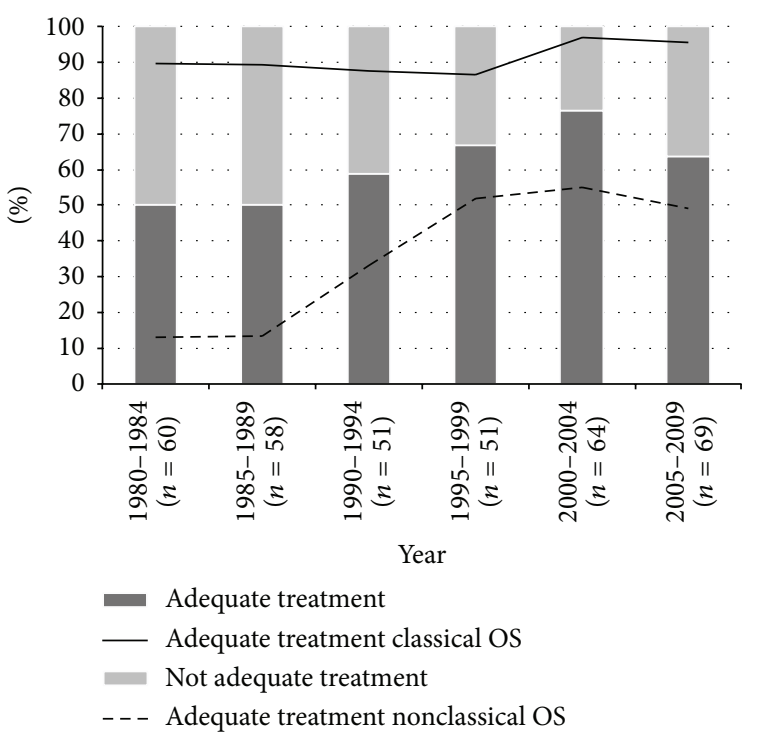

(a)

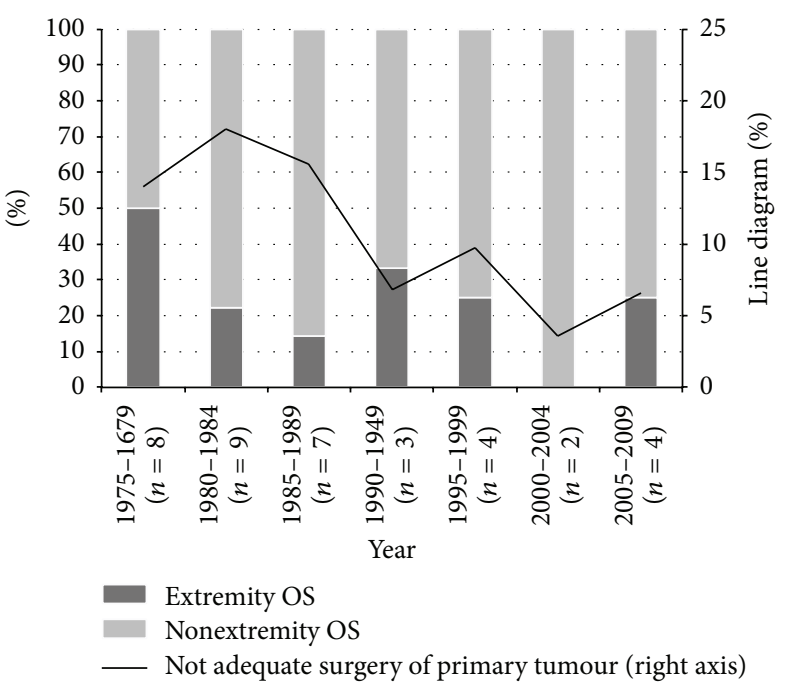

(b)

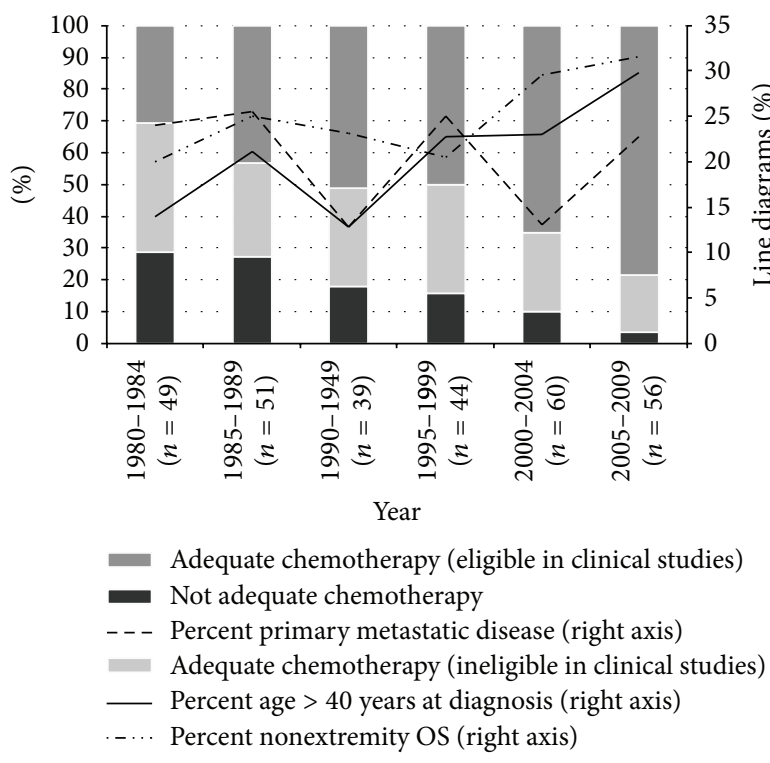

(c)

FIGURE 2: Time trends in distribution of osteosarcoma (OS) patients according to different subgroups: adequate versus not adequate primary treatment (both surgery and chemotherapy), including the percentage of adequate treatment among classical and nonclassical OS (a). The distribution of not adequate primary surgery among extremity versus nonextremity OS (b). Adequate versus not adequate chemotherapy. The percentage of patients $>40$ years of age at diagnosis, primary metastatic disease, and nonextremity tumour that received chemotherapy (c).

the 56 COS patients not receiving adequate chemotherapy (28\%), 39 were treated according to the previously mentioned CAMOS combination. From 1980 and onwards 91\% of all COS received adequate treatment.

NCOS. In this group, only $33 \%$ (72 patients) received adequate treatment for the whole time period (Table 3) and 37\% from 1980 to 2009. As expected, the reason for inadequacy was dominated by incomplete or absence of surgery in patients with primary metastatic disease or axial tumours, by inadequate chemotherapy in elderly patients, and by inadequacy of both modalities in patients with several factors combined (Table 3 ).

\subsection{Treatment-Time Trends}

Adequate Primary Treatment. The percentage of adequate treatment increased from $50 \%$ during the 1980 s to $64 \%$ since 2005 (Figure 2(a)). We could also document an improved treatment during the 1990s for the NCOS group, with just 

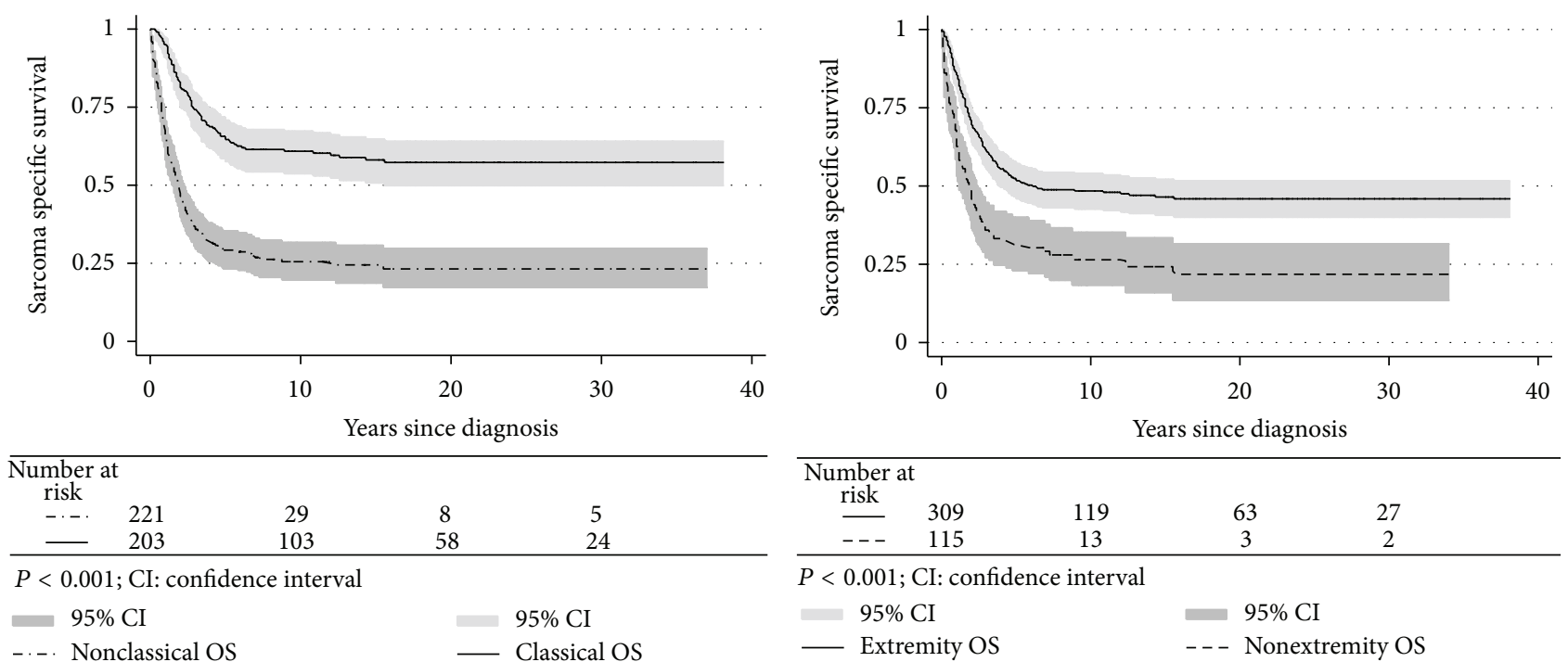

(a)

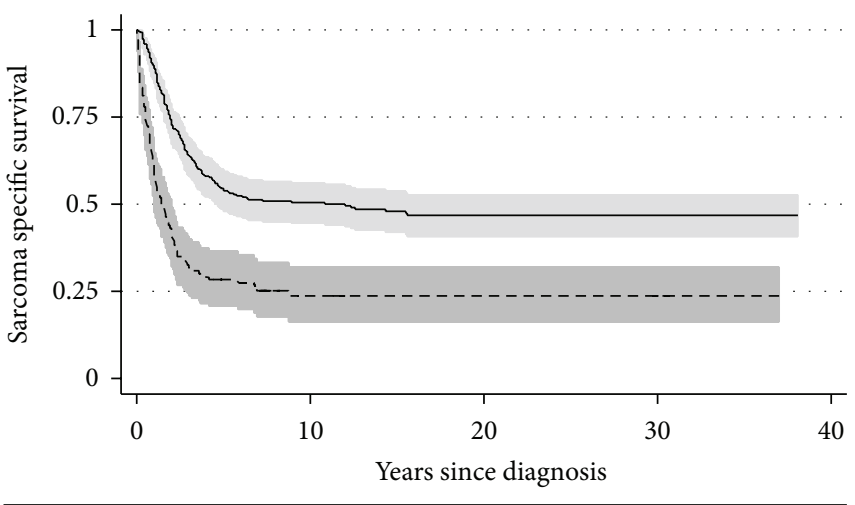

\begin{tabular}{|c|c|c|c|c|}
\hline \multicolumn{5}{|c|}{ Number at } \\
\hline & 337 & 124 & 63 & 28 \\
\hline--- & 84 & 8 & 3 & 1 \\
\hline \multicolumn{5}{|c|}{$P<0.001$; CI: confidence interval } \\
\hline \multicolumn{3}{|c|}{$95 \% \mathrm{CI}$} & \multicolumn{2}{|c|}{$95 \% \mathrm{CI}$} \\
\hline \multicolumn{3}{|c|}{ _ No primary metastasis } & \multicolumn{2}{|c|}{ _ _ - Primary metastasis } \\
\hline
\end{tabular}

(c)

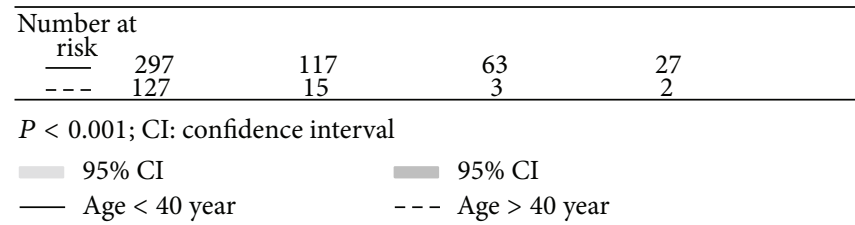

(d)

FIGURE 3: Sarcoma specific survival of classical versus nonclassical osteosarcoma (OS) patients (a). Extremity versus nonextremity OS (b). Patients with and without metastasis at time of diagnosis (c). Patients above and below 40 years of age at time of diagnosis (d).

over $50 \%$ adequate treatment since 1995 , in contrast to slightly above $95 \%$ among COS patients since the millennium.

Adequate Surgery. For surgically treated patients we observed a reduction in the frequency of inadequate surgery of primary tumour from about $18 \%$ to approximately 5\% since the millennium (Figure 2(b)). 27\% of the inadequately treated primary tumours (10 patients) were related to a tumour in the appendicular skeleton. Four of these 10 patients had primary metastatic disease and five were above 40 years of age at time of diagnosis. Correspondingly, 27 patients with inadequate surgery had their primary tumour in the axial skeleton.

Surgical Procedures. Extremity OS patients were amputated during the 1970s (55 patients) with only one exception. We confirmed the significant increase in limb salvage procedures since the 1980s [5, 41-43], although amputation remains a valid procedure in selected cases of OS [44]. The percentage of amputation decreased from 89\% during 1980-84 to $18 \%$ since the millennium. Since $1980,97 \%$ of all surgical procedures for primary extremity tumours revealed adequate margins, with no significant differences between amputation and other surgical procedures $(P=0.235)$. Six cases with uncertain margins were excluded from this analysis. However, $69 \%$ of all patients in the amputated group had adequate combined treatment compared to $87 \%$ in the other group during 1980-2009 ( $P=0.001)$. This difference was due to fewer patients with adequate chemotherapy in the first mentioned group. Hence, there was a significant difference in SSS between these two groups since 1980 ( RR $=1.7,95 \%$ 

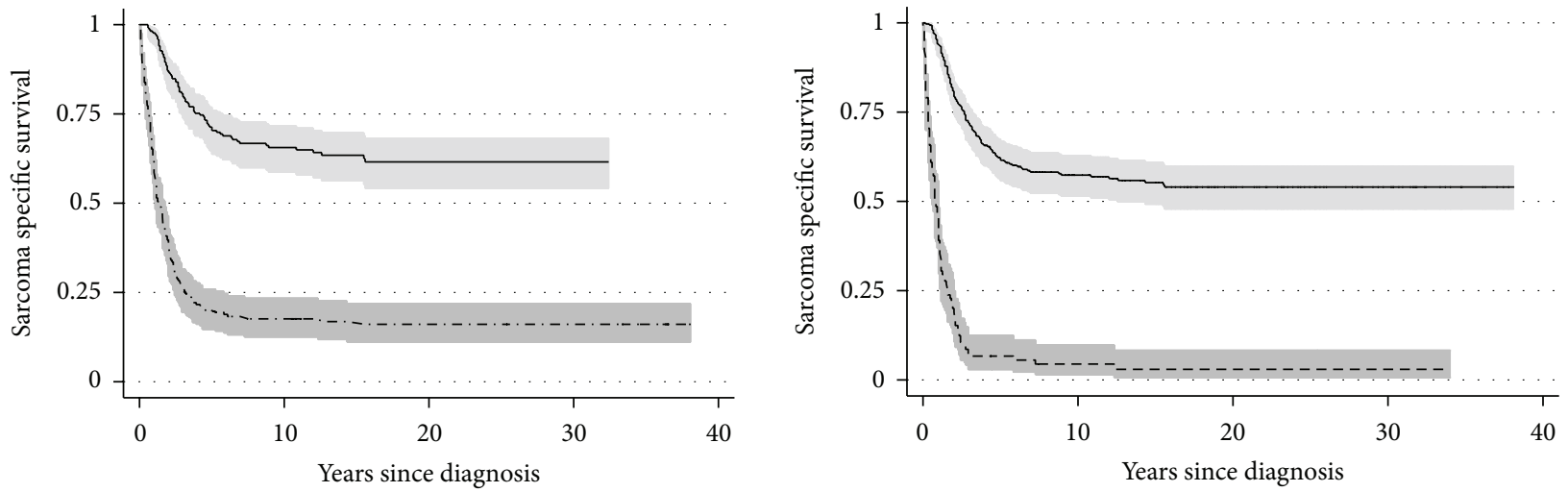

\begin{tabular}{ccccc}
\hline $\begin{array}{c}\text { Number at } \\
\text { risk }\end{array}$ & & & & \\
$-\cdot-$ & 202 & 26 & 21 & 17 \\
& 216 & 104 & 43 & 11 \\
\hline
\end{tabular}

$P<0.001 ;$ CI: confidence interval; six uncertain cases were excluded

$\begin{array}{ll} & 95 \% \text { CI } \\ -. . & \text { Not adequate }\end{array}$

95\% CI

— Adequate

\begin{tabular}{|c|c|c|c|c|}
\hline \multicolumn{5}{|c|}{ Number at } \\
\hline$\overline{-1-}$ & $\begin{array}{l}305 \\
108\end{array}$ & $\begin{array}{c}128 \\
3\end{array}$ & $\begin{array}{c}64 \\
2\end{array}$ & $\begin{array}{c}28 \\
1\end{array}$ \\
\hline
\end{tabular}

$P<0.001 ;$ CI: confidence interval; 11 uncertain cases were excluded

(a)

$\begin{array}{lll} & 95 \% \mathrm{CI} & 95 \% \mathrm{CI} \\ - & \text { Adequate surgery } \quad--- & \text { Inadequate or no surgery }\end{array}$

(b)
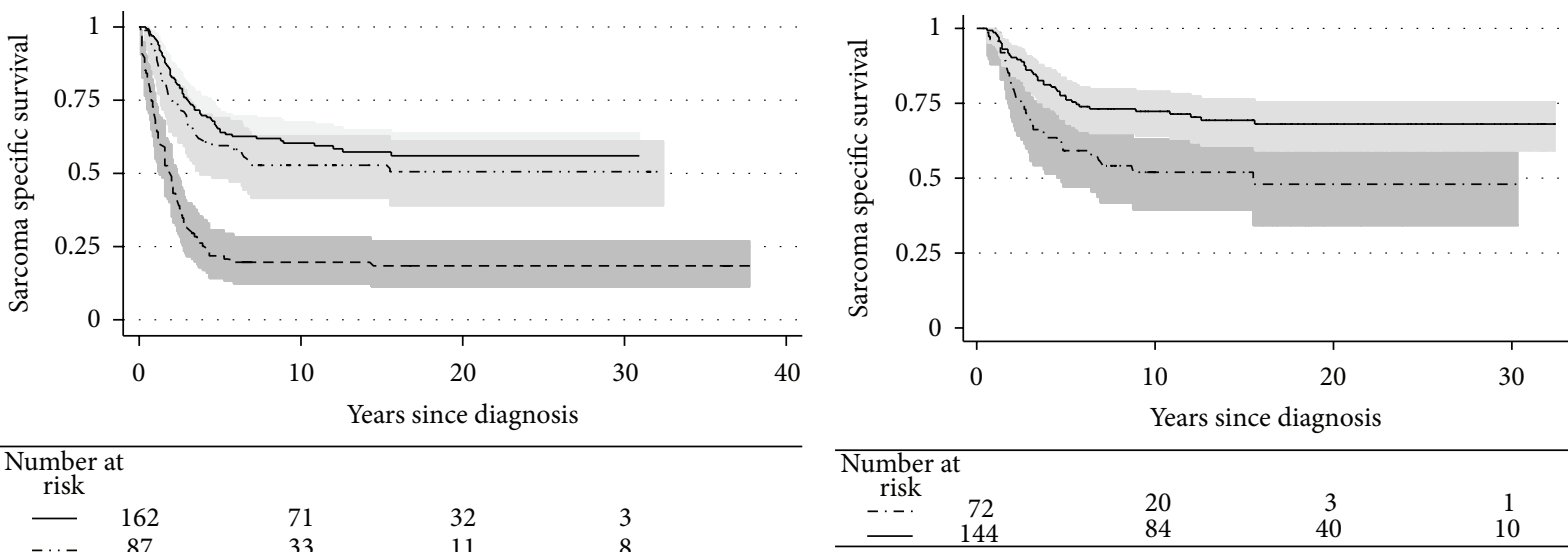

\begin{tabular}{lcllc}
\hline $\begin{array}{l}\text { Number at } \\
\text { risk }\end{array}$ & & & & \\
- & 162 & 71 & 32 & 3 \\
$-\cdots-$ & 87 & 33 & 11 & 8 \\
--- & 170 & 25 & 21 & 17 \\
\hline
\end{tabular}

$P<0.001$ (adequate versus inadequate); CI: confidence interval; five uncertain cases were excluded

$P=0.003 ;$ CI: confidence interval

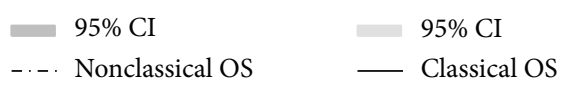

\begin{tabular}{|c|c|}
\hline 95\% CI & $95 \%$ CI \\
\hline $95 \% \mathrm{CI}$ & —_ Adequate (eligible) \\
\hline
\end{tabular}

(c)

(d)

FIGURE 4: Sarcoma specific survival for osteosarcoma (OS) patients dependent on adequate primary treatment (both surgery and chemotherapy) (a); adequate surgery (b); adequate chemotherapy (c); adequate primary treatment among classical versus nonclassical OS (d).

CI 1.1-2.4, $P=0.011)$. No corresponding conclusion regarding adequately treated patients during 1980-2009 could be drawn, although RR was estimated to 1.5 (95\% CI $0.9-2.5$, $P=0.106)$.

Adequate Chemotherapy. We observed an increase in the percentage of OS patients with adequate chemotherapy from 1980-2009 (Figure 2(c)). Correspondingly, the percentage of patients given adequate chemotherapy and enrolled in prospective clinical studies increased from the 1980s and onwards. 119 patients (83\%) in the COS group with adequate chemotherapy were included in the consecutive trials. 43 patients in the NCOS group (41\%) were also included in clinical studies, that is, 15 in Euroboss 1 [25], 13 in EURAMOS 1 [25], 13 in ISG/SSG II [23], one in SSG VIII [21], and one in SSG II [20], respectively. The latter two cases were later excluded from these studies due to verified lung metastases just weeks after time of diagnosis. $42 \%$ of the 83 patients that received adequate chemotherapy and included in clinical trials since the millennium were NCOS. 
Figure 2(c) also illustrates the improved time trends of chemotherapy to elderly patients and those with primary tumour in the axial skeleton from 1980 to 2009. No corresponding trend was seen among patients with primary metastatic disease (Figure 2(c)).

\subsection{Metastatic Relapse or Local Recurrence during Followup.} Among patients without primary metastatic disease, $42 \%$ of the nonextremity OS (39 patients) and 50\% with extremity OS (124 patients) developed metastases during followup $(P=0.317)$. Approximately $90 \%$ developed lung metastases. Among patients with axial OS and no primary metastatic disease, 32\% (29 patients) experienced local relapse during followup compared to $4 \%$ (9 patients) among extremity OS $(P<0.001)$. The median time to first metastatic event or local recurrence were 1.3 years (range 11.5 years) and 1.1 years (range 10.3 years) from diagnosis, respectively.

$45 \%$ of the patients with local recurrence (17 patients) were never diagnosed with metastasis during followup and 16 were related to relapses in the axial skeleton (11 cases in the skull or jaw, four in costa, and one in the clavicle). 12 of these patients died due to their local relapse and without metastasis.

3.5. Survival Analyses. The survival rates in elderly people, patients with axial OS, or metastatic disease at time of diagnosis (Figures 3(b)-3(d)) were inferior to COS (Figure 3(a)). 10 -year SSS for the latter group was $61 \%$ in contrast to $26 \%$ for the NCOS. As expected, patients who received adequate treatment had significantly better survival than inadequately treated patients (Figures 4(a)-4(c)). We also found a significant difference in survival among adequately treated COS versus NCOS patients (Figure 4(d)).

Patients enrolled in prospective studies (170 patients) had significantly better SSS than the 254 cases not formally included $(\mathrm{RR}=0.4,95 \% \mathrm{CI} 0.3-0.6, P<0.001)$. However, among the group that received both adequate surgery and chemotherapy (216 patients) we could not demonstrate any significant difference in SSS between the 148 patients formally included into clinical trials and the corresponding 68 patients treated according to the different protocols $(\mathrm{RR}=1.1,95 \% \mathrm{CI}$ $0.7-1.8, P=0.618)$.

3.6. Prognostic Factors. Table 4 presents the results of univariate analysis as ten-year overall survival and EFS according to different characteristics of OS including time periods and the main treatments variables. Histological subgroups $(P=0.167 / 0.435, \log$ rank $)$ and amputation versus other surgeries $(P=0.113 / 0.067$, log rank) were not included in Table 4 . We observed essentially the same positive prognostic factors influencing survival as shown in Table 2 . All treatment variables presented had a positive and significant impact on outcome (Table 4).

Multivariate analyses of the prognostic factors significant by univariate analysis in Table 4 are presented in Table 5 . We have not taken into account multiple imputation of missing values in this report, since their effects were considered as modest. Adequate primary treatment, elevated $\mathrm{LDH}$, and decade of diagnosis were all significant factors for overall survival and EFS. Primary metastatic disease, age $>40$ years, and elevated tumour size were also adverse factors for overall survival, whereas axial tumour localisation did not reach significance (Table 5). Further, NCOS was an adverse factor for overall survival $(\mathrm{RR}=2.0,95 \% \mathrm{CI} 1.4-2.9, P<0.001)$.

Some main characteristics of the 216 patients receiving adequate primary treatment are displayed in Table 6 . Female gender had a significantly improved overall survival among all adequately treated patients $(\mathrm{RR}=1.9)$. We observed also just minor differences in RR between all patients with primary metastatic disease $(\mathrm{RR}=3.1$, Table 4$)$ and those in this group that received adequate treatment $(\mathrm{RR}=2.9$, Table 6$)$. Patients with either axial OS or age $>40$ years had a larger difference in RR, but the observed difference was not statistically significant with uncertainty due to the limited number of observations (data not shown).

\section{Discussion}

This population-based study provides reliable evidence that the overall outcome of an unselected cohort of patients with high-grade OS is less impressive than widely assumed (Figure 3 and Table 4). To our knowledge, no previous nationwide studies have in detail analysed the NCOS group, representing just over half of the patients in our cohort. We have by purpose not reported too detailed information regarding the clinical variables, in order to reduce the number of missing variables. Still, we believe that our key variables are valid to expand our knowledge regarding especially the NCOS population.

About $30 \%$ of our patients were above 40 years of age at time of diagnosis in line with previous nationwide studies [14, 16], although somewhat lower than reported by Whelan et al. [17]. As previously reported [10], just over one-fourth of all patients had an axial OS and one-fifth primary metastatic disease. For the latter group we found no differences among patients with primary tumour in the axial versus appendicular skeleton, in contrast to a previous report [45]. However, only $5 \%$ in the study of Bielack et al. had tumour located in the axial skeleton. This makes direct comparison difficult.

We confirmed a higher male to female ratio in extremity compared to nonextremity tumour [46]. Although gender had a significant effect on survival for adequately treated patients in the current study (Table 6), we identified no corresponding effect for all patients (Table 4). Nevertheless, there seems to be no unanimous answer regarding the relationship of sex on survival in the available literature [15, $16,42,47-50]$.

We found larger primary lesions among patients with primary metastatic disease (Table 2 ) in line with a previous study [51]. Patients with axial primary tumours had on average smaller lesions than patients with extremity localised tumours. This seems reasonable due to less "space" for tumour growth, for example, spine or head and neck region. Elevated tumour size was an independent prognostic factor for outcome (Table 5).

The presence of a pathologic fracture, typically in the weight-bearing extremity skeleton, was significantly higher 
among elderly patients (Table 2), despite a lower percentage of extremity OS among the elderly; this is in line with the literature $[9,10,17]$. Osteoporosis may be one contributing factor in this regard. Pathologic fracture has been considered as a poor prognostic factor [52] but did not reach significance in our analysis for the whole cohort (Table 4).

We found a dismal SSS among NCOS versus COS patients (Figure 3(a)). However, "less adequate" treatment could not explain the entire discrepancy in SSS between these two groups (Figure 4(d)). One important reason for the latter observation could be the poor prognosis for patients with primary metastatic disease, independent of given treatment (see below). In addition, nonextremity tumours have been associated with a higher rate of local recurrence than extremity OS, while no corresponding differences regarding first metastatic event were documented [46]. We confirmed these results in the present study. Both local recurrence and metastatic relapse are associated with rather poor prognosis [53-57], even though postrelapse survival seems to be higher among patients with late relapse [58].

Adequate primary treatment, regarding both surgery and chemotherapy, had a positive prognostic impact on survival in this study (Table 5). As previously reported $[9,10,16]$, we also confirmed the improvement in overall survival since the late 1970s mainly due to the use of multiagent chemotherapy $[9,59]$.

We could not verify any stage migration over time due to better imaging [60] since we observed a fluctuation among patients with primary metastatic disease between 1975 and 2009. However, the "true" incidence could be confounded by low numbers of patients, approximately 2-3 cases annually within this time frame.

$\mathrm{LDH}$ was also an independent adverse prognostic factor in our study, in line with the literature $[47,61,62]$. However, we found no significant impact of ALP on outcome in the Cox analysis, in contrast to previous reports $[63,64]$.

Primary metastatic disease was a strong negative prognostic factor in our study (Tables 4-6), in line with the literature $[14,42,51,65-68]$. The poor results may relate to primary chemotherapy resistance [8] partly due to different biologic characteristics of these tumours [51] and the numbers of metastases at diagnosis [69] besides the absence of complete surgical remission [69]. Hence, new therapeutic approaches at initial presentation are warranted for the primary metastatic OS patients $[8,65,66,70]$.

We observed just a minor adverse impact on survival of age $>40$ years among adequately treated patients $(R R=1.3)$ in contrast to all elderly patients in the cohort $(\mathrm{RR}=2.7)$. It has earlier been advocated that patients above 40 years should, whenever possible, be treated similarly to those in younger age group [71]. Still, more than $77 \%$ of all elderly patients in this study received inadequate primary treatment from 1975-09, mainly due to inadequate chemotherapy (Table 3). Age $>40$ years at diagnosis was also a significant adverse factor in the multivariate analyses for overall survival but not for EFS (Table 5). Hence, more information regarding this group of patients, including their tolerance to chemotherapy, is warranted, for example, the results from the ongoing Euroboss 1 protocol [25].
It is well established that axial localisation results in worse outcome than primary disease arising in the appendicular skeleton $[33,46,48,72]$. This is partly explained by a higher rate of axial tumours in the elderly patients. We have far too many cases with inadequate surgery among our patients with axial OS (Table 3 and Figure 2(b)), with local relapse as a frequent consequence.

Overall, we confirm primary metastatic disease, elevated tumour size, elevated serum LD, and old age as adverse prognostic factors in line with the literature $[6,7]$. Neither elevated serum ALP nor axial primary tumour site were significantly adverse factors in the present study in contrast to previous findings $[6,7]$. Nevertheless, differences in risk assessment might occur due to inequalities in, for example, methods adopted to identify and to analyse the various prognostic factors in different studies. The results may also depend on the clinical and demographic characteristics of the OS population analysed.

We cannot rule out that not including histologic response to preoperative chemotherapy may have affected the results in Table 5. Our decision was based on the different grading systems used from 1975 to 2009 [8], and the preoperative multidrug combinations have also changed considerably since the introduction by Rosen et al. [73]. These variables have already been fully published in the publications from the consecutive trials of the SSG (II, VIII, XIV) [20, 21, 24] and the ISG/SSGI [22]. More active drugs have also been added to the preoperative schedules and the time-line has been extended [8].

In addition, we could not evaluate a histological response to chemotherapy without a complete and uniform histological reexamination of all cases in the cohort. As of today only about $20 \%$ of all cases were formally reexamined histologically as part of this project [10]. However, a consequential and significant disadvantage of such an approach is the lack of available histological specimens for reexamination. For example, a previous Finnish study experienced a drop-out rate of $34 \%$ due to missing original specimens in such a setting [15]. Hence, we have chosen not to include histological response to chemotherapy in this paper since we believe the potential disadvantage will exceed the potential gain of such an approach.

Further improving cure rates for osteosarcoma continue to be challenging $[1,9,74,75]$. To our knowledge, this is the first study addressing scopes beyond the classical OS patients based on a nationwide, population-based study. Differences in treatment could only partly explain the dismal outcome of NCOS patients as they present other tumour biological characteristics and clinical challenges compared to the COS.

\section{Disclosure}

The NCR has approved the use of these data for international publishing.

\section{Disclaimer}

The authors alone are responsible for the content and writing of the paper. 


\section{Conflict of Interests}

The authors declare no conflict of interests regarding the publication of this paper.

\section{Acknowledgments}

The authors would like to thank Sigbjørn Smeland, Clinical Director, Oslo University Hospital, and Gunnar Sæter, Scientific Director, Institute for Cancer Research, Oslo University Hospital, for their valuable feedback. This project was supported by the South-Eastern Norway Regional Health Authority Research Program, with a pilot project supported by the National Resource Centre for Sarcomas in Norway.

\section{References}

[1] J. Whelan, B. Seddon, and M. Perisoglu, "Management of osteosarcoma," Current Treatment Options in Oncology, vol. 7, no. 6, pp. 444-455, 2006.

[2] N. Jaffe, "Osteosarcoma: review of the past, impact on the future. The American experience," Cancer Treatment and Research, vol. 152, pp. 239-262, 2009.

[3] S. Ferrari, E. Palmerini, E. L. Staals et al., "The treatment of nonmetastatic high grade osteosarcoma of the extremity: review of the Italian Rizzoli experience. Impact on the future," Cancer Treatment and Research, vol. 152, pp. 275-287, 2009.

[4] S. Bielack, H. Jürgens, G. Jundt et al., "Osteosarcoma: the COSS experience," Cancer Treatment and Research, vol. 152, pp. 289308, 2009.

[5] Ø. S. Bruland, H. Bauer, T. Alvegaard, and S. Smeland, "Treatment of osteosarcoma. The Scandinavian Sarcoma Group experience," Cancer Treatment and Research, vol. 152, pp. 309318, 2009.

[6] S. Bielack, D. Carrle, and P. G. Casali, "Osteosarcoma: ESMO clinical recommendations for diagnosis, treatment and followup," Annals of Oncology, vol. 20, no. 4, pp. iv137-iv139, 2009.

[7] P. C. Hogendoorn, N. Athanasou, S. Bielack, and et al, "Bone sarcomas: ESMO clinical practice guidelines for diagnosis, treatment and follow-up," Annals of Oncology, vol. 21, supplement 5, pp. v204-v213, 2010.

[8] Ø. S. Bruland and A. Pihl, "On the current management of osteosarcoma. A critical evaluation and a proposal for a modified treatment strategy," European Journal of Cancer, vol. 33, no. 11, pp. 1725-1731, 1997.

[9] A. Luetke, P. A. Meyers, I. Lewis, and H. Juergens, "Osteosarcoma treatment-where do we stand? A state of the art review," Cancer Treatment Reviews, vol. 40, no. 4, pp. 523-532, 2014.

[10] K. Berner, T. B. Johannesen, A. Berner et al., "Time-trends on incidence and survival in a nationwide and unselected cohort of patients with skeletal osteosarcoma," Acta Oncologica, vol. 54, no. 1, pp. 25-33, 2015.

[11] S. E. Larsson and R. Lorentzon, "The geographic variation of the incidence of malignant primary bone tumors in Sweden," The Journal of Bone and Joint Surgery-American Volume, vol. 56, no. 3, pp. 592-600, 1974.

[12] S. Harvei and O. Solheim, "The prognosis in osteosarcoma: norwegian national data," Cancer, vol. 48, no. 8, pp. 1719-1723, 1981.

[13] C. A. Stiller, S. J. Passmore, M. E. Kroll, P. A. Brownbill, J. C. Wallis, and A. W. Craft, "Patterns of care and survival for patients aged under 40 years with bone sarcoma in Britain, 1980-1994," British Journal of Cancer, vol. 94, no. 1, pp. 22-29, 2006.

[14] H. Curry, G. Horne, P. Devane, and H. Tobin, "Osteosarcoma in New Zealand: an outcome study comparing survival rates between 1981-1987 and 1994-1999," The New Zealand Medical Journal, vol. 119, no. 1242, Article ID U2234, 2006.

[15] M. M. Sampo, M. Tarkkanen, A. H. Kivioja, M. H. Taskinen, R. Sankila, and T. O. Böhling, "Osteosarcoma in Finland from 1971 through 1990: a nationwide study of epidemiology and outcome," Acta Orthopaedica, vol. 79, no. 6, pp. 861-866, 2008.

[16] M. Sampo, M. Koivikko, M. Taskinen et al., "Incidence, epidemiology and treatment results of osteosarcoma in Finlanda nationwide population-based study," Acta Oncologica, vol. 50, no. 8, pp. 1206-1214, 2011.

[17] J. Whelan, A. McTiernan, N. Cooper et al., "Incidence and survival of malignant bone sarcomas in England 1979-2007," International Journal of Cancer, vol. 131, no. 4, pp. E508-E517, 2012.

[18] M. S. Kim, S.-Y. Lee, W. H. Cho et al., "Prognostic effects of doctor-associated diagnostic delays in osteosarcoma," Archives of Orthopaedic and Trauma Surgery, vol. 129, no. 10, pp. 14211425, 2009.

[19] P. Rustad, P. Felding, L. Franzson et al., “The Nordic Reference Interval Project 2000: recommended reference intervals for 25 common biochemical properties," Scandinavian Journal of Clinical and Laboratory Investigation, vol. 64, no. 4, pp. 271-283, 2004.

[20] G. Saeter, T. A. Alvegard, I. Elomaa, A. E. Stenwig, T. Holmstrom, and O. P. Solheim, "Treatment of osteosarcoma of the extremities with the T-10 protocol, with emphasis on the effects of preoperative chemotherapy with single-agent highdose methotrexate: a Scandinavian Sarcoma Group study," Journal of Clinical Oncology, vol. 9, no. 10, pp. 1766-1775, 1991.

[21] S. Smeland, C. Müller, T. A. Alvegard et al., "Scandinavian Sarcoma Group Osteosarcoma Study SSG VIII: prognostic factors for outcome and the role of replacement salvage chemotherapy for poor histological responders," European Journal of Cancer, vol. 39, no. 4, pp. 488-494, 2003.

[22] S. Ferrari, S. Smeland, M. Mercuri et al., "Neoadjuvant chemotherapy with high-dose ifosfamide, high-dose methotrexate, cisplatin, and doxorubicin for patients with localized osteosarcoma of the extremity: a joint study by the italian and Scandinavian Sarcoma Groups," Journal of Clinical Oncology, vol. 23, no. 34, pp. 8845-8852, 2005.

[23] K. Boye, A. B. Del Prever, M. Eriksson et al., "High-dose chemotherapy with stem cell rescue in the primary treatment of metastatic and pelvic osteosarcoma: final results of the ISG/SSG II study," Pediatric Blood \& Cancer, vol. 61, no. 5, pp. 840-845, 2014.

[24] S. Smeland, Ø. S. Bruland, L. Hjorth et al., "Results of the Scandinavian Sarcoma Group XIV protocol for classical osteosarcoma: 63 patients with a minimum follow-up of 4 years," Acta Orthopaedica, vol. 82, no. 2, pp. 211-216, 2011.

[25] D. Carrle and S. S. Bielack, "Current strategies of chemotherapy in osteosarcoma," International Orthopaedics, vol. 30, no. 6, pp. 445-451, 2006.

[26] N. Marina, S. Bielack, J. Whelan et al., "International collaboration is feasible in trials for rare conditions: the EURAMOS experience," Cancer Treatment and Research, vol. 152, pp. 339353, 2009.

[27] EURAMOS, 2014, http://212.219.75.232/euramos/. 
[28] S. Bielack, S. Smeland, J. Whelan et al., "MAP plus maintenance pegylated interferon $\alpha-2 b$ (MAPIfn) versus MAP alone in patients with resectable high-grade osteosarcoma and good histologic response to preoperative MAP: first results of the EURAMOS-1 'good response' randomization," Journal of Clinical Oncology, vol. 31, supplement, abstract LBA10504, 2013.

[29] EURAMOS-1-Poor-Response-Randomisation1, 2014, http:// www.ssg-org.net/wp-content/uploads/2011/03/EURAMOS-1Poor-Response-Randomisationl.pdf.

[30] R. Schwarz, O. Bruland, A. Cassoni, P. Schomberg, and S. Bielack, "The role of radiotherapy in osteosarcoma," Cancer Treatment and Research, vol. 152, pp. 147-164, 2009.

[31] A. Hershey, G. D. Bos, and K. Stevens, "Successful treatment of spinal osteosarcoma with radiation and chemotherapy," Orthopedics, vol. 19, no. 7, pp. 617-618, 1996.

[32] M. M. Hernberg, A. H. Kivioja, T. O. Böhling, R. J. Janes, and T. A. Wiklund, "Chemoradiotherapy in the treatment of inoperable high-grade osteosarcoma," Medical Oncology, vol. 28, no. 4, pp. 1475-1480, 2011.

[33] G. Sæter and $\varnothing$. S. Bruland, "High-grade osteosarcoma: the scope beyond the classical patient," in Towards the Eradication of Osteosarcoma Metastasis-An Odyssey, pp. 21-23, 1998.

[34] J. K. Anninga, H. Gelderblom, M. Fiocco et al., "Chemotherapeutic adjuvant treatment for osteosarcoma: where do we stand?" European Journal of Cancer, vol. 47, no. 16, pp. 24312445, 2011.

[35] W. F. Enneking, S. S. Spanier, and M. A. Goodman, "A system for the surgical staging of musculoskeletal sarcoma," Clinical Orthopaedics and Related Research, vol. 153, pp. 106-120, 1980.

[36] E. L. Kaplan and P. Meier, "Nonparametric estimation from incomplete observations," Journal of the American Statistical Association, vol. 53, pp. 457-481, 1958.

[37] N. Mantel, "Evaluation of survival data and two new rank order statistics arising in its consideration," Cancer Chemotherapy Reports, vol. 50, no. 3, pp. 163-170, 1966.

[38] D. R. Cox, "Regression models and life-tables," Journal of the Royal Statistical Society. Series B. Methodological, vol. 34, pp. 187-220, 1972.

[39] P. Brandal, B. Bjerkehagen, Ø. S. Bruland, S. Skjeldal, T. V. Bogsrud, and K. S. Hall, "Synchronous and metachronous skeletal osteosarcomas: the Norwegian Radium Hospital experience," Acta Oncologica, vol. 48, no. 8, pp. 1165-1172, 2009.

[40] W. R. Gilks, S. Richardson, and D. J. Spiegelhalter, Markov Chain Monte Carlo in Practice, Interdisciplinary Statistics, Chapman \& Hall, London, UK, 1996.

[41] H. Tsuchiya and K. Tomita, "Prognosis of osteosarcoma treated by limb-salvage surgery: the ten-year intergroup study in Japan," Japanese Journal of Clinical Oncology, vol. 22, no. 5, pp. 347-353, 1992.

[42] S. S. Bielack, B. Kempf-Bielack, G. Delling et al., "Prognostic factors in high-grade osteosarcoma of the extremities or trunk: an analysis of 1,702 patients treated on neoadjuvant cooperative osteosarcoma study group protocols," Journal of Clinical Oncology, vol. 20, no. 3, pp. 776-790, 2002.

[43] G. Bacci, S. Ferrari, S. Lari et al., "Osteosarcoma of the limb: amputation or limb salvage in patients treated by neoadjuvant chemotherapy," The Journal of Bone \& Joint Surgery-British Volume, vol. 84, no. 1, pp. 88-92, 2002.

[44] G. A. Marulanda, E. R. Henderson, D. A. Johnson, G. D. Letson, and D. Cheong, "Orthopedic surgery options for the treatment of primary osteosarcoma," Cancer Control, vol. 15, no. 1, pp. 1320, 2008.
[45] S. S. Bielack, B. Wulff, G. Delling et al., "Osteosarcoma of the trunk treated by multimodal therapy: experience of the Cooperative Osteosarcoma study group (COSS)," Medical and Pediatric Oncology, vol. 24, no. 1, pp. 6-12, 1995.

[46] G. Saeter, O. S. Bruland, G. Folleras, M. Boysen, and J. Hoie, "Extremity and non-extremity high-grade osteosarcoma-the Norwegian Radium Hospital experience during the modern chemotherapy era," Acta Oncologica, vol. 35, supplement 8, pp. 129-134, 1996.

[47] G. Bacci, A. Longhi, S. Ferrari et al., "Prognostic significance of serum lactate dehydrogenase in osteosarcoma of the extremity: experience at Rizzoli on 1421 patients treated over the last 30 years," Tumori, vol. 90, no. 5, pp. 478-484, 2004.

[48] M. U. Jawad, M. C. Cheung, J. Clarke, L. G. Koniaris, and S. P. Scully, "Osteosarcoma: improvement in survival limited to high-grade patients only," Journal of Cancer Research and Clinical Oncology, vol. 137, no. 4, pp. 597-607, 2011.

[49] J. S. Whelan, R. C. Jinks, A. McTiernan et al., "Survival from high-grade localised extremity osteosarcoma: combined results and prognostic factors from three European Osteosarcoma Intergroup randomised controlled trials," Annals of Oncology, vol. 23, no. 6, pp. 1607-1616, 2012.

[50] M. Collins, M. Wilhelm, R. Conyers et al., "Benefits and adverse events in younger versus older patients receiving neoadjuvant chemotherapy for osteosarcoma: findings from a metaanalysis," Journal of Clinical Oncology, vol. 31, no. 18, pp. $2303-$ 2312, 2013.

[51] G. Bacci, S. Ferrari, A. Longhi et al., "High-grade osteosarcoma of the extremity: differences between localized and metastatic tumors at presentation," Journal of Pediatric Hematology/Oncology, vol. 24, no. 1, pp. 27-30, 2002.

[52] S. P. Scully, M. A. Ghert, D. Zurakowski, R. C. Thompson, and M. C. Gebhardt, "Pathologic fracture in osteosarcoma: prognostic importance and treatment implications," The Journal of Bone and Joint Surgery. American Volume, vol. 84, no. 1, pp. 49-57, 2002.

[53] G. Saeter, J. Høie, A. E. Stenwig, A. K. Johansson, E. Hannisdal, and O. P. Solheim, "Systemic relapse of patients with osteogenic sarcoma. Prognostic factors for long term survival," Cancer, vol. 75, no. 5, pp. 1084-1093, 1995.

[54] B. Kempf-Bielack, S. S. Bielack, H. Jürgens et al., "Osteosarcoma relapse after combined modality therapy: An analysis of unselected patients in the Cooperative Osteosarcoma Study Group (COSS)," Journal of Clinical Oncology, vol. 23, no. 3, pp. 559-568, 2005.

[55] G. Bacci, C. Forni, A. Longhi et al., "Local recurrence and local control of non-metastatic osteosarcoma of the extremities: a 27-year experience in a single institution," Journal of Surgical Oncology, vol. 96, no. 2, pp. 118-123, 2007.

[56] D. Carrle and S. Bielack, "Osteosarcoma lung metastases detection and principles of multimodal therapy," Cancer Treatment and Research, vol. 152, pp. 165-184, 2009.

[57] M. Franke, J. Hardes, K. Helmke et al., "Solitary skeletal osteosarcoma recurrence. Findings from the Cooperative Osteosarcoma Study Group," Pediatric Blood and Cancer, vol. 56, no. 5, pp. 771-776, 2011.

[58] S. Ferrari, A. Briccoli, M. Mercuri et al., "Late relapse in osteosarcoma," Journal of Pediatric Hematology/Oncology, vol. 28, no. 7, pp. 418-422, 2006. 
[59] G. Rosen, C. Tan, A. Sanmaneechai, E. J. Beattie Jr., R. Marcove, and M. L. Murphy, "The rationale for multiple drug chemotherapy in the treatment of osteogenic sarcoma," Cancer, vol. 35, no. 3, supplement, pp. 936-945, 1975.

[60] A. R. Feinstein, D. M. Sosin, and C. K. Wells, “The Will Rogers phenomenon. Stage migration and new diagnostic techniques as a source of misleading statistics for survival in cancer," The New England Journal of Medicine, vol. 312, no. 25, pp. 1604-1608, 1985.

[61] G. Bacci, S. Ferrari, L. Sangiorgi et al., "Prognostic significance of serum lactate dehydrogenase in patients with osteosarcoma of the extremities," Journal of Chemotherapy, vol. 6, no. 3, pp. 204-210, 1994.

[62] S. Ferrari, G. Bacci, P. Picci et al., "Long-term follow-up and post-relapse survival in patients with non-metastatic osteosarcoma of the extremity treated with neoadjuvant chemotherapy," Annals of Oncology, vol. 8, no. 8, pp. 765-771, 1997.

[63] G. Bacci, A. Longhi, S. Ferrari et al., "Prognostic significance of serum alkaline phosphatase in osteosarcoma of the extremity treated with neoadjuvant chemotherapy: recent experience at Rizzoli Institute," Oncology Reports, vol. 9, no. 1, pp. 171-175, 2002.

[64] G. Bacci, A. Longhi, M. Versari, M. Mercuri, A. Briccoli, and P. Picci, "Prognostic factors for osteosarcoma of the extremity trerated with neoadjuvant chemotherapy: 15 -year experience in 789 patients treated at a single institution," Cancer, vol. 106, no. 5, pp. 1154-1161, 2006.

[65] P. A. Meyers, G. Heller, J. H. Healey et al., "Osteogenic sarcoma with clinically detectable metastasis at initial presentation," Journal of Clinical Oncology, vol. 11, no. 3, pp. 449-453, 1993.

[66] M. B. Harris, P. Gieser, A. M. Goorin et al., "Treatment of metastatic osteosarcoma at diagnosis: a Pediatric Oncology Group Study," Journal of Clinical Oncology, vol. 16, no. 11, pp. 3641-3648, 1998.

[67] G. Bacci, A. Briccoli, M. Rocca et al., "Neoadjuvant chemotherapy for osteosarcoma of the extremities with metastases at presentation: recent experience at the Rizzoli Institute in 57 patients treated with cisplatin, doxorubicin, and a high dose of methotrexate and ifosfamide," Annals of Oncology, vol. 14, no. 7, pp. 1126-1134, 2003.

[68] V. Mialou, T. Philip, C. Kalifa et al., "Metastatic osteosarcoma at diagnosis: prognostic factors and long-term outcome-the French pediatric experience," Cancer, vol. 104, no. 5, pp. 11001109, 2005.

[69] L. Kager, A. Zoubek, U. Pötschger et al., "Primary metastatic osteosarcoma: presentation and outcome of patients treated on neoadjuvant cooperative osteosarcoma study group protocols," Journal of Clinical Oncology, vol. 21, no. 10, pp. 2011-2018, 2003.

[70] G. Bacci, M. Rocca, M. Salone et al., "High grade osteosarcoma of the extremities with lung metastases at presentation: treatment with neoadjuvant chemotherapy and simultaneous resection of primary and metastatic lesions," Journal of Surgical Oncology, vol. 98, no. 6, pp. 415-420, 2008.

[71] R. J. Grimer, S. R. Cannon, A. M. Taminiau et al., "Osteosarcoma over the age of forty," European Journal of Cancer, vol. 39, no. 2, pp. 157-163, 2003.

[72] T. Ozaki, S. Flege, U. Liljenqvist et al., "Osteosarcoma of the spine: experience of the Cooperative Osteosarcoma Study Group," Cancer, vol. 94, no. 4, pp. 1069-1077, 2002.

[73] G. Rosen, R. C. Marcove, B. Caparros, A. Nirenberg, C. Kosloff, and A. G. Huvos, "Primary osteogenic sarcoma. The rationale for preoperative chemotherapy and delayed surgery," Cancer, vol. 43, no. 6, pp. 2163-2177, 1979.

[74] S. S. Bielack, "Osteosarcoma: time to move on?" European Journal of Cancer, vol. 46, no. 11, pp. 1942-1945, 2010.

[75] D. S. Geller and R. Gorlick, "Osteosarcoma: a review of diagnosis, management, and treatment strategies," Clinical Advances in Hematology and Oncology, vol. 8, no. 10, pp. 705-718, 2010. 


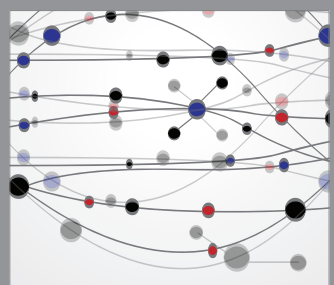

The Scientific World Journal
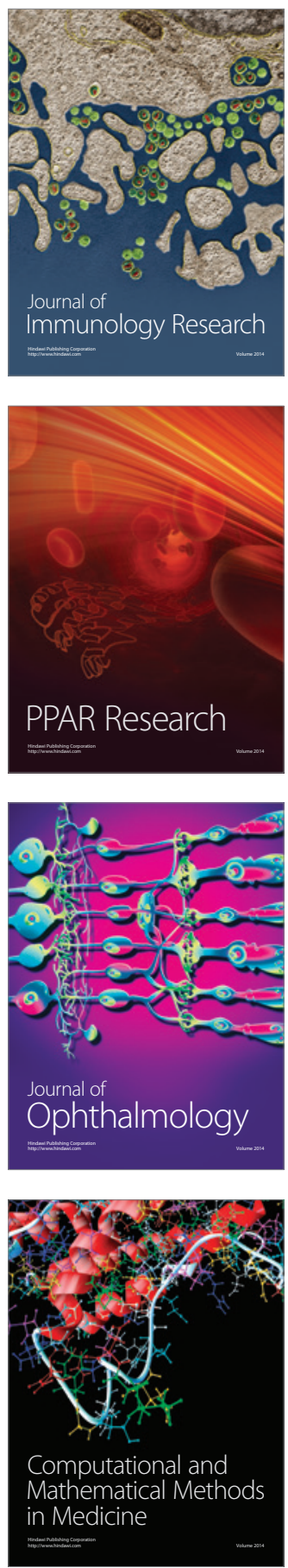

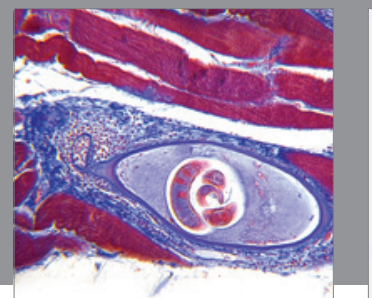

Gastroenterology

Research and Practice
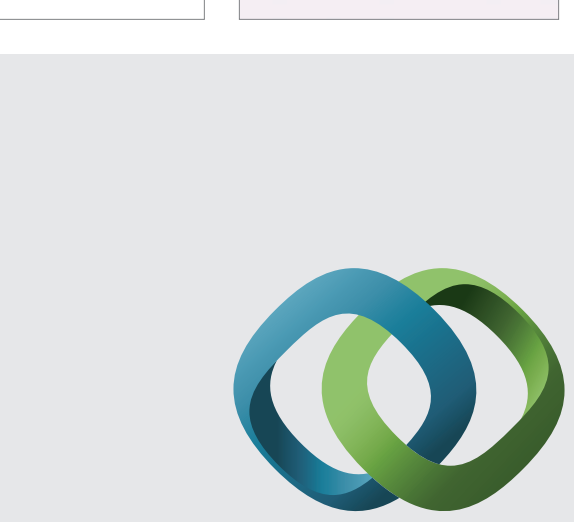

\section{Hindawi}

Submit your manuscripts at

http://www.hindawi.com
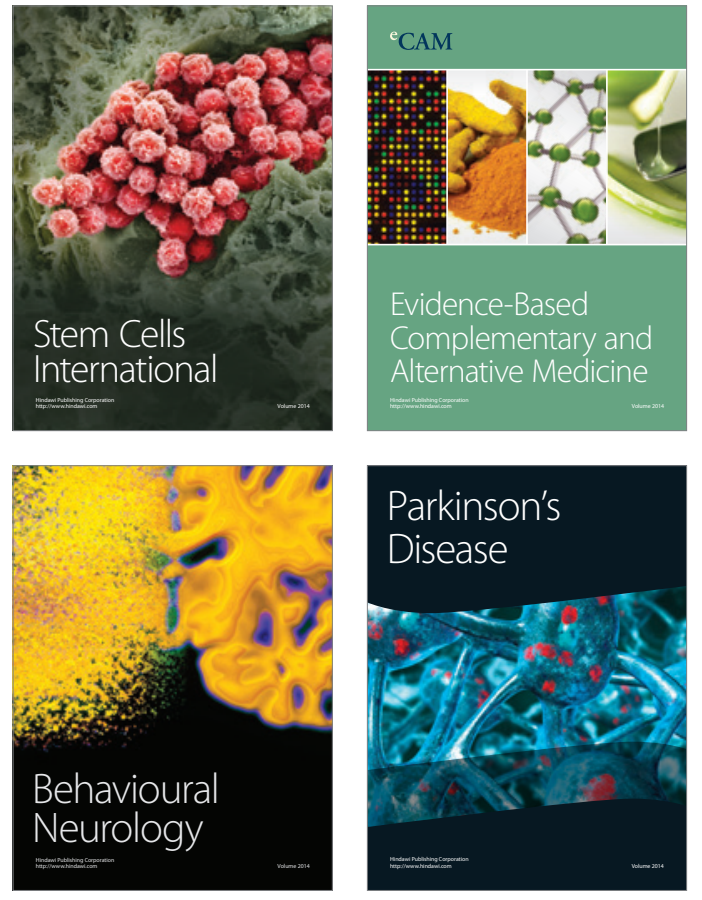
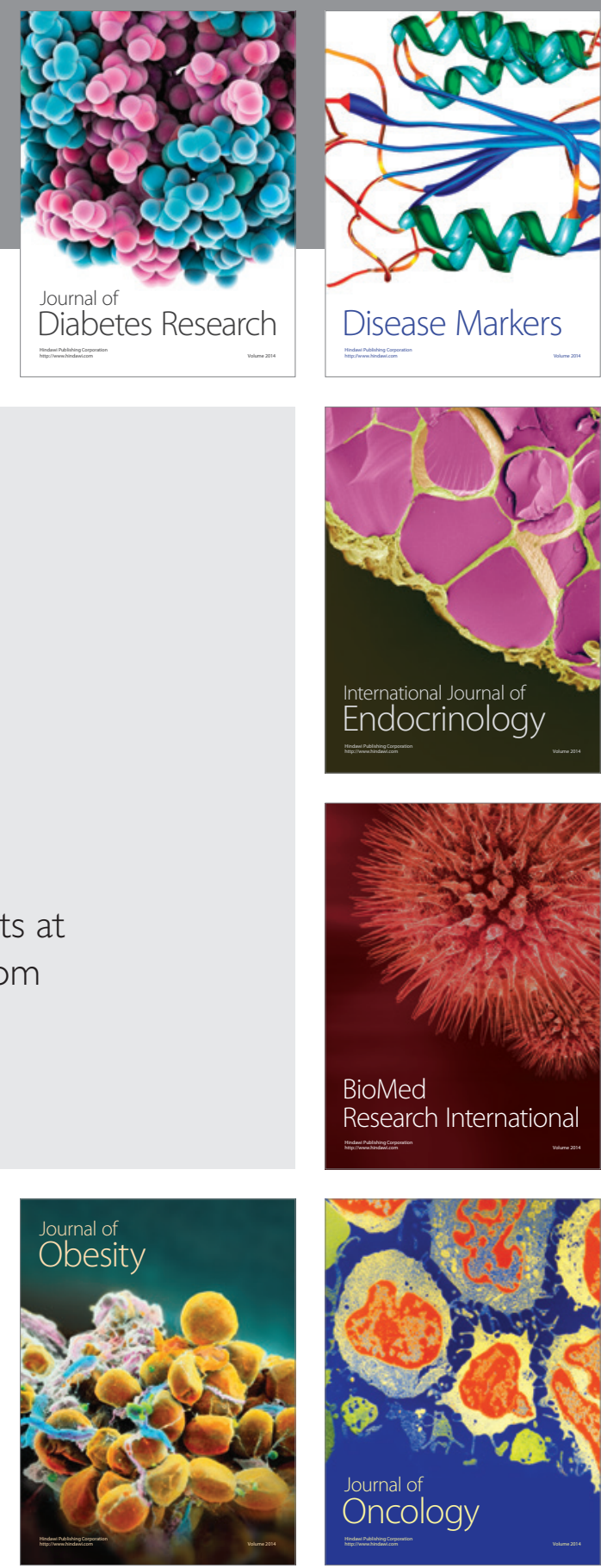

Disease Markers
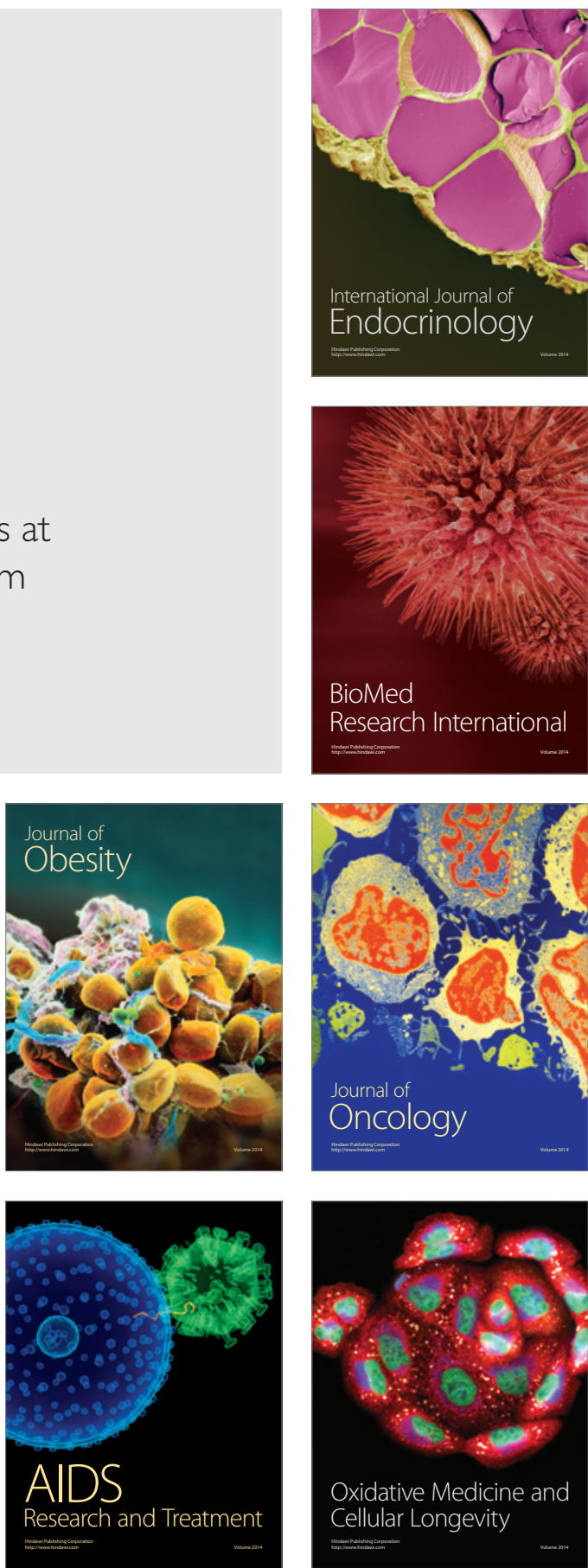